\title{
MITO E HISTÓRIA NA CIDADE ENCANTADA DE AFUÁ
}

\author{
Myth and history in the enchanted city of Afuá
}

\section{Carmentilla das Chagas Martins* Cledson Moraes Evangelista**}

\begin{abstract}
RESUMO: Desde a década de 1970, gradativamente a região amazônica vem sendo considerada como uma das condições de existência da vida humana no planeta. Os múltiplos sentidos derivados dessa premissa impulsionaram um conjunto de intervenções políticas e econômicas que não se processaram sem contradições em relação à dimensão social e cultural. Considera-se que esses processos assinalam a modernização de muitos lugares na Amazônia brasileira. Este artigo busca entender como se combinam na vida cotidiana de ribeirinhos os sentidos existenciais atribuídos pelo mito/continuidades e pela história/rupturas nos imaginários amazônicos. Foram utilizadas no desenvolvimento do trabalho fontes orais e escritas, coletadas na cidade de Afuá (PA) durante o ano de 2019, bem como uma literatura histórica e antropológica. Desse modo, observa-se que os ribeirinhos, diante das contradições postas pela modernização de seus lugares de vida, operam as continuidades de seu imaginário para se apropriarem das rupturas que assinalam suas vivências cotidianas.
\end{abstract}

Palavras-chave: Mito. História. Ribeirinhos.

\begin{abstract}
Since the 1970s, the Amazon region has gradually been considered as one of the conditions for the existence of human life on the planet. The multiple meanings derived from this premise boosted a set of political and economic interventions that did not happen without contradictions in relation to the social and cultural dimension. These processes are considered to signal the modernization of many places in the Brazilian Amazon. This article seeks to understand how the existential meanings attributed by myth/continuities and history/ruptures in the Amazonian imaginary are combined in the daily life of riverside residents. Oral and written sources, collected in the city of Afuá (PA) in 2019, were used in the development of the study, as well as historical and anthropological literature. Thus, it is observed that the riverside residents, faced with the contradictions posed by the modernization of their places of life, operate the continuities of their imaginary to appropriate the ruptures that mark their daily experiences.
\end{abstract}

Keywords: Myth. History. Riverside residents.

\footnotetext{
* Doutora em Ciências Sociais, com atuação profissional na graduação e pós-graduação na Universidade Federal do Amapá. Desenvolve pesquisas sobre fronteiras e mobilidades transfronteiriças, imaginários e representações sociais. E-mail carmentilla.c@gmail.com ORCID: http://orcid.org/0000-0001-6308-1096

** Graduado em História, desenvolve pesquisas nas áreas de história cultural da Amazônia. Coordenador geral do Centro Acadêmico de História no biênio 2016-17. Desenvolveu atividades como bolsista no Centro de Estudos e Pesquisas Arqueológicas do Amapá-CEPAP-Universidade Federal do Amapá. E-mail clemoraes65@gmail.com
} 


\section{Introdução}

Ao findar o século XX, o significado da Amazônia ganhou novos atributos devido ao dilema estabelecido em torno de seu papel na equação sobrevivência humana versus capital natural, sendo considerada, nos termos de Becker (2006, p. 33), o coração ecológico do planeta. Em vista disso, as populações amazônicas são confrontadas com transformações em diferentes escalas, as quais não se fazem sem contrastes e contradições (FRAXE; WITKOSKI; MIGUEZ, 2009).

No contexto de transições importa estudar padrões menos cambiantes da vida dos indivíduos para compreender a alteridade cultural no tempo-espaço da e na Amazônia. O ponto de partida é o diálogo interdisciplinar entre história e antropologia, o qual possibilita aventuras na longa duração braudeliana, sem incorrer na fossilização da história (VAINFAS, 1997). A interdisciplinaridade entre história e antropologia cultural foi essencial para a inclusão do campo simbólico nas análises das formas de organização social, considerando-se que palavras e imagens têm mais a dizer do que aquilo que era indicado nos registros materiais.

O objetivo deste artigo $^{1}$ é abordar a relação entre mito e história como chave de interpretação do imaginário em vivências cotidianas de indivíduos ribeirinhos, considerando-se a concepção de ribeirinho nos termos de Rente Neto e Furtado (2015), segundo a qual o rio é um importante mediador das relações sociais. E nessas circunstâncias, o imaginário é formado por valores que interferem na interação dos humanos com o ambiente aquático, se generalizando como práticas no processo da reprodução da vida social.

No artigo são examinados os mitos do Kutruku e da Cobra Grande, conforme as narrativas das fontes orais e outros documentos, tendo em perspectiva as mudanças ocorridas na paisagem urbana de Afuá/PA. A cidade como produto dos indivíduos que nela vivem e se reproduzem ao longo do tempo, traz inscrições que lhe especificam no espaço. O mito reconhecido como conhecimento perdeu a qualificação de inconsistente e incongruente, passando à categoria de narrativa, cujas significações explicam e/ou ordenam a vida social (FAULHABER, 2000).

Para desenvolver a investigação foi realizada uma pesquisa de campo durante o ano de 2019. Foram aplicados quatorze questionários a um grupo de homens e mulheres com idades entre 09 e 67 anos e a redundância foi o critério selecionado para sistematizar os dados orais, ou melhor dizendo: as repetições nas respostas indicavam o momento em que o objetivo tinha sido alcançado. Também foram examinados: i) o programa comemorativo do aniversário de Afuá, transmitido pela rádio Afuá FM no dia 02 de agosto de 2019; ii) uma pintura sem designação de autoria referente ao mito do Kutruku; iii) o acervo de documentos - poemas, lendas, cantigas populares e programas da festividade de Nossa Senhora da Conceição - que estão na Biblioteca Pública Municipal Professora Belkiss Santos, naquela cidade.

As relações que os indivíduos estabelecem com a natureza proporcionam a criação de imagens sobre suas experiências cotidianas numa associação com situações análogas no passado, bem como a projeção para orientar outras no porvir. Hartog (2014), ao analisar a obra Raça e história, de Claude Lévy-Strauss, aponta para a diversidade de culturas no tempo. Essa premissa revela que não existem culturas isoladas e imunes ao tempo, sendo de fato relevante reconhecer a diversidade como processo histórico, e não as concepções que, em que cada época, lhe foram atribuídas.

O texto se organiza, além desta introdução, em quatro partes: a caracterização do lócus de estudo; o recorte do imaginário como objeto dos estudos históricos; a relação entre mito e história;

1 Pesquisa realizada sem financiamento. 
e as considerações finais.

\section{Memórias e notas etnográficas: algumas considerações sobre Afuá}

A cidade de Afuá é a sede do município homônimo, situado no arquipélago do Marajó foz do rio Amazonas. Geograficamente o município faz fronteira com os municípios paraenses de Chaves, Breves, Anajás, Gurupá e com o estado do Amapá, do qual se separa pelo canal do Norte. Uma de suas principais características é a situação dos terrenos alagadiços onde se assenta a cidade, configurando-se assim como área de várzea. De acordo com o Instituto Brasileiro de Geografia Estatística-IBGE (2014), o município possui uma área total $8.372,795 \mathrm{~km}^{2}$, sendo $1,7 \mathrm{~km}^{2}$ de área urbana. Sua população equivale a 37.004 habitantes, e destes, $73 \%$ vivem em pequenos vilarejos ribeirinhos. Atualmente, Afuá compõe o quadro dos 144 municípios pertencentes ao estado do Pará.

A origem do nome da cidade é envolta em mistério e diferentes narrativas são engendradas a seu respeito, marcando assim um conflito em sua definição. Sobre isto, a Igreja de Nossa Senhora da Conceição (1983), por meio das palavras de Ferreira Pena, defende que Afuá é "uma palavra que não é nem portuguesa nem de origem indígena”, mas não especifica de onde o termo provém. Outra versão sobre a origem do nome revela que este é um topônimo indígena originado do termo "Arafuá", que significaria "terra de fogo". Além dessas, uma última narrativa, bem mais difundida entre os ribeirinhos, é a de que um boto batizou a cidade ao emergir das águas "querendo falar", produzindo um som. Segundo a tradição oral, "fuá" seria o som produzido pelo boto na ocasião em que emergiu para respirar.

Afuá possui múltiplas denominações, projetando-se para os visitantes e para a mídia sob os títulos de: i) "Veneza Marajoara", em razão das grandes águas de março que anualmente lhe invadem; ii) "cidade de Maria", em decorrência da forte influência do catolicismo popular e de sua santa padroeira, Imaculada Conceição; iii) "terra do bicitáxi”, devido à engenhoca criativa, inovação feita a partir da bicicleta e que responde à demanda de sua população em relação à falta de automóveis; iv) "cidade das bicicletas", em decorrência do grande número de exemplares existentes no local; v) "terra do festival do camarão", em homenagem a um dos maiores festivais culturais do arquipélago do Marajó; e vi) "cidade do açaí", pela abundância do fruto.

A toponímia é um atributo da relação que as pessoas mantêm com os lugares; esse processo faz parte da construção do imaginário, onde são encontradas paisagens nomeadas e renomeadas, numa sobreposição que expressa múltiplas temporalidades, ou seja, diversas formas de articular passado, presente e futuro (HARTOG, 2014). Portanto, o fato de Afuá ter variadas denominações possibilita a reflexão sobre os modos como seus moradores fazem a história da cidade no fluxo de suas histórias de vida.

Devido à insularidade e por não haver integração terrestre com outras localidades, é o transporte fluvial que assegura a acessibilidade ao espaço urbano. Cumpre destacar que esse acesso está vinculado ao regime das marés, e isso implica em certa instabilidade no funcionamento do sistema. Além dos rios é possível também chegar à cidade pelo ar em aviões monomotores ${ }^{3}$.

2 Vicente Pizón teria sido o descobridor da ilha do Marajó, inicialmente batizada Ilha Grande de Joanes; renomeada em 1754 como Marajó, que em tupi significa "barreira do mar" (BRASIL, 2006 apud DIAS; SILVA, 2011).

3 Embora exista um aeroporto na cidade desde dezembro de 1988, ainda não existe uma empresa aérea que faça linha direta para o lugar. 
As ruas da cidade são passarelas sobre o terreno de várzea, onde a cidade foi sendo construída, majoritariamente construídas em madeira, à exceção daquelas situadas na área central, que são de concreto. A mudança no material usado para construir as ruas indica um movimento de transformação estética, iniciado em 26 de julho de 1983. Para seus moradores essa transição é positiva, pois acreditam que o concreto (material que substituiu a madeira) é símbolo de desenvolvimento e progresso. Em relação aos benefícios da mudança, no ano de 1986, por ocasião da festa de Nossa Senhora da Conceição, a programação impressa apontava para o fato de que "Afuá é uma cidade com muitas mudanças: as ruas e pontes de madeiras estão sendo trocadas por ruas de concreto sobre pilares, pegando muita largura, o que beneficia espaço livre para andar e para as crianças brincarem” (PAROQUIA DE AFUÁ, 1983, não paginado).

As principais atividades econômicas geradoras de emprego e renda são baseadas na pesca e no extrativismo vegetal, destacando-se a exploração do palmito, de madeiras e do açaí. Também é marcante na cidade a pesca e comercialização do camarão, que por sua abundância e valor cultural recebe no mês de julho um festival em sua homenagem. O Festival do Camarão é notadamente uma das maiores manifestações culturais do arquipélago do Marajó, atraindo anualmente entre 40 a 50 mil visitantes ao município e fortalecendo, assim, seu potencial turístico e econômico.

A infraestrutura urbana descrita torna inviável a circulação de veículos automotores e os afuaenses fazem da bicicleta o instrumento de mobilidade. $\mathrm{Na}$ "cidade das bicicletas" surgiu o bicitáxi, invenção de Raimundo Gonçalves, popularmente conhecido como Sarito. Segundo Simões (2014) o bicitáxi surgiu em 1995 quando

Sarito montou o primeiro modelo de bicitáxi, com três rodas, e em 2000, desenvolveu a versão que seria recriada por toda a cidade: da união de duas bicicletas, fundidas por uma estrutura de metal, surgia um veículo com quatro rodas. Ainda movido pelo pedal, mas com aparência e status de carro (SIMÕES, 2014, p. 19).

Para Simões (2014), o bicitáxi passou por um processo de recriação popular atravessando um movimento de transformações, mas são seus usos que revelam transformações na dinâmica urbana de Afuá. Os bicitáxis passaram a atender aos serviços públicos relativos à saúde e energia elétrica; transporte escolar e carro-som de publicidade; ou mesmo na política e nos projetos de evangelização das igrejas (bicitáxis das igrejas Assembleia de Deus, Universal do Reino de Deus e Igreja Nossa Senhora da Conceição) (SIMÕES, 2014, p. 26).

Enquanto a bicicleta possibilita o transporte de até duas pessoas, o bicitáxi se apresenta como uma alternativa locomotiva, possibilitando o carregamento de até seis pessoas. A princípio o bicitáxi fora projetado para o transporte familiar, segundo conta seu inventor em entrevista a Olímpio Guarany ${ }^{4}$. Depois passou a transportar pessoas pelas ruas da cidade, situação que o converteu em fonte de renda, à semelhança dos táxis. Por fim disseminou-se de modo a evoluir para símbolo da cidade, alcançando um status de patrimônio cultural do município e ocupando lugar privilegiado no Festival do Camarão, ocasião em que acontece a biciata, competição para escolha da bicicleta, do triciclo e do bicitáxi com mais bela ornamentação. Cabe observar que na produção dessas ornamentações os competidores procuram representar o modo de ser e viver ribeirinho.

A cidade se divide em dois grandes bairros, Central e Capim Marinho. Além dessa organização administrativa, o município tem unidades que organizam o espaço citadino para ações

\footnotetext{
4 OLÍMPIO GUARANY TV. Afuá, a vida sobre as águas. Afuá, 29 de jul. 2018. Reportagem. Disponível em: https://www.youtube.com/watch?v=ZlzjdpSRAlw. Acesso em: 22 jul. 2020.
} 
missionárias da Paróquia de Afuá: no bairro Central são Nossa Senhora do Perpétuo Socorro, São Sebastião, Santa Rita e Santa Mônica; no bairro do Capim Marinho são Nossa Senhora do Bom Remédio, Santo Expedito, Nossa Senhora de Nazaré e São Benedito.

Como já referido, a cidade carrega múltiplas denominações, transformando-se e se ressignificando no curso do tempo, num processo dialético permeado por contradições que emergem das modificações espaço-tempo. Portanto, como afirmam Dias e Silva (2011),

A cidade enquanto fenômeno histórico não pode ser analisada como algo pronto e acabado, pois ela está em constante processo de mudanças, de transformação, ou seja, ela vive em um perpétuo processo de produção-destruição-(re)produção, haja vista, que ela é produto das relações travadas entre os homens ao longo do tempo (DIAS; SILVA, 2011, p. 2).

Tais experiências no tempo remetem ao processo de ocupação da cidade de Afuá, datado no século XIX. Uma das pioneiras, Dona Micaela Ferreira, se estabeleceu nas terras por volta do ano de 1845. De acordo com a Paróquia de Afuá (2012, p. 3), esta ocupação se deu aproximadamente entre os anos de 1842 e 1845, sendo oficialmente registrada na freguesia de Chaves ${ }^{5}$ em 30 de janeiro de $1854^{6}$, numa porção de terra equivalente à meia légua de extensão, isto é $3.300 \mathrm{~m}$, então denominada de Sítio Santo Antônio.

Com os terrenos devidamente registrados, por volta de $1868 \mathrm{em}$ torno da casa de dona Micaela já existiam muitas barracas devido ao lugar ter excelente localização para um porto e ponto de paragem, ocasião em que o núcleo populacional configurava-se como "uma espécie de ancoradouro seguro no qual as embarcações aportavam à espera da subida da maré para prosseguirem viagem, uma vez que, nessa região, existem bancos de areia que com a maré baixa colocam em risco a navegação nesse curso fluvial” (DIAS; SILVA, 2011, p. 8).

\section{0 imaginário na história cultural}

Atualmente, o imaginário se apresenta como um fértil campo de pesquisa para os historiadores da cultura que buscam, a partir deste conceito, estudar as imagens visuais, mentais e verbais produzidas pelas sociedades. Porém, cabe lembrar que nem sempre os imaginários coletivos foram valorizados pelos historiadores, visto que o pensamento racional e científico tradicionalmente o considerou como algo ilusório ou fantasioso. Nesse sentido cabe lembrar que, em termos cartesianos, o imaginário derivava do erro e da falsidade, constituindo uma forma inicial de conhecimento. Essa separação do saber racional em relação ao imaginário chegou ao século XIX, época em que o cientificismo foi tomado como critério de verdade em oposição ao ilusório e a ficção contidos, elementos recorrentes no imaginário (VAINFAS, 1997).

Foi somente com a ocorrência da chamada crise dos paradigmas que a história e outras ciências sociais puderam romper com antigos modelos e conceitos explicativos da realidade. Pesavento ressalva que foi no âmbito dessas transformações que começou a se organizar uma nova especialidade: a história cultural, cuja proposta é "decifrar a realidade do passado por meio das suas representações, tentando chegar àquelas formas, discursivas e imagéticas, pelas quais os homens expressaram a si próprios e o mundo" (PESAVENTO, 2014, p. 42).

\footnotetext{
5 Atualmente, município do estado do Pará com população estimada, em 2019, em 23.717 pessoas (IBGE, 2020).

${ }^{6}$ De acordo com lei de terras vigente no Brasil, regulamentada pelo decreto Lei n. 1.318, de 20 de janeiro de 1854.
} 
Embora a história do imaginário e a história das mentalidades estejam assentadas no mesmo campo, o mental, uma não se confunde com a outra. A diferença está no fato de que as mentalidades discutem as sensibilidades, ou "os modos de sentir", enquanto o imaginário lida com as imagens no campo do simbólico, nas representações (BARROS, 2007).

Porém, tal reorientação na escrita da história, bem como na maneira com a qual os historiadores estudaram o passado, se desenvolveu lentamente. Ainda assim, pouco a pouco as ideias que concebiam o imaginário não mais como fantasia, mas sim como parte integrante da realidade foram tomando conta das ciências humanas, incluída nesse movimento a história. O excerto a seguir apresenta a importância desse conceito para o estudo da alteridade cultural no tempo, pois

A introdução desse conceito-chave no âmbito das ciências humanas foi fundamental para a recuperação das dimensões da cultura realizadas nos anos [19]80 pelos historiadores, pela atenção que dava ao processo de construção mental da realidade, produtor de coesão social e de legitimidade de uma ordem social instituída, por meio de ideias, imagens e práticas dotadas de significados que os homens elaboravam para si (PESAVENTO, 2014, p. 24).

O sentido da realidade social é construído no curso do tempo, onde são configurados os significados que orientam as práticas sociais na existência objetiva dos indivíduos. O imaginário guarda memórias que integram diferentes temporalidades, tornando possível haver reciprocidade entre diferentes gerações. Ou melhor, constitui conteúdos sociais de compreensão compartilhada por todos os indivíduos, sendo "[...] um saber-fazer que organiza o mundo, produzindo a coesão ou o conflito" (PESAVENTO, 2014, p. 43).

Entre outras funções, o imaginário é gerador de crenças, manifesta-se no mágico, estimula a criação de mitos, pauta as representações coletivas e institui o cotidiano por meio da arte, da literatura e diferentes formas de instituições. O imaginário participa então da construção do real, que nada mais é do que "a interpretação que os homens atribuem à realidade", sendo ela um fenômeno dado a ser percebido e interpretado, existente a partir das ideias, dos signos e dos símbolos (LA PLANTINE; TRINDADE, 2003, p. 11-12).

Sendo o imaginário uma construção social, em cada contexto sócio-histórico existem condições que tornam possível a produção dos imaginários que, juntamente com outros tipos de conhecimento - filosófico, histórico, científico -, atribuem sentidos à realidade dos indivíduos. O imaginário é qualificado tanto pela vivência coletiva quanto subjetiva, e da intersecção dessas dimensões ele constitui representações do real e aciona estratégias de ação.

Afuá é uma ilha, parte do arquipélago do Marajó, e a vida social e material de seus moradores está estritamente vinculada com os rios, os quais "[...] influenciam o ritmo da atividade humana em seu conjunto mais amplo e que são ao mesmo tempo marcados pelos traços humanos dentro de certas características particulares inerentes ao processo de adaptação do homem àquele espaço" (RENTE NETO; FURTADO, 2015, p. 178).

Além disso são populações que vivem entre o visível e o invisível, instâncias formuladoras de magia, crenças, ideias, imagens, valores, práticas sociais; todas essas referências, imersas num mundo aquático, definem imaginários coletivos. É comum entre os ribeirinhos a crença na existência de encantados, seres que moram nas matas e/ou no fundo dos rios, sendo também forte a devoção aos santos e santas do credo católico. 


\section{Mito e história: ressignificações de uma cidade encantada}

As discussões envolvendo as relações entre mito e história têm resultado em bons frutos às comunidades de historiadores e historiadoras. De um lado estaria a história comprometida com um esforço intelectual para organizar, selecionar e interrogar fontes que dariam origem a uma construção narrativa sobre a realidade existencial dos homens no tempo. De outro lado se teria o mito, narrativa concebida como inverdade, invenção, ficção, mentira.

Para Rocha (1994, p. 22), o mito é uma narrativa de “[...] tal simplicidade que só poder ser complexa. A meio caminho entre a lição e o engano. Tão nítida e tão plena de significações, tão abstrata e tão concreta, tão familiar e tão estranha". Sendo reflexão que carrega vários significados, sem roteiro pré-concebido, ao reunir resíduos de vida coletiva e os infundir nos imaginários acaba por admitir muitas interpretações. O mito se apropria dos significados produzidos pelos indivíduos em diferentes tempos-espaços e suas metáforas traduzem em signos a objetividade da vida social.

Em outra perspectiva está a história, que postula haver "[...] possibilidade da produção de histórias: de acordo com as relações respectivas do presente, do passado e do futuro, determinados tipos de história são possíveis e outros não" (HARTOG, 2014, p. 39). Na mesma direção segue o argumento de Isabel Barca em seu estudo sobre educação histórica em Portugal: “[...] o raciocínio histórico necessita de um quadro substantivo sólido e coerente para que assuma as potencialidades da História de estabelecer relações entre passado, presente e cenários possíveis de futuro e que podem ser expressos pela narrativa" (BARCA, 2019, p. 118).

Observa-se que a história estabelece regimes de historicidade, construindo menos certezas sobre o que de fato tenha acontecido e mais a consciência de que passado, presente e futuro constituem um contiunum. A escrita da história corresponde a um processo dialético, no qual em cada presente se escreve sobre um passado e se projetam expectativas sobre um futuro. Assim também é o mito, manifesto como uma construção narrativa que, como a história, possui suas especificidades. O mito, admite Rocha

[...] é uma narrativa. É um discurso, uma fala. É uma forma de as sociedades espelharem suas contradições, exprimirem seus paradoxos, dúvidas e inquietações. Pode ser visto como uma possibilidade de se refletir sobre a existência, o cosmos, as situações de 'estar no mundo' ou as relações sociais (ROCHA, 1994, p. 7).

Esse autor ressalva que o mito não é qualquer narrativa, ele se apresenta de forma especial, se distingue das demais narrativas humanas, apresenta particularidades; carrega mensagens cifradas, por isto é passível de interpretação; fala, mas não de forma direta; ele esconde algo, mas o faz poeticamente. Aquilo que ele pretende dizer não está dado de forma explícita, sua mensagem não se apresenta de maneira óbvia e direta; eles têm algo a dizer, e essa fala possui conteúdo produzido e impulsionado pelo imaginário. O mito é capaz de revelar muitas coisas, entre elas as representações que os homens fazem de si e do mundo, e nesse sentido o

[...] mito é, pois, capaz de revelar o pensamento de uma sociedade, a sua concepção da existência e das relações que os homens devem manter entre si e com o mundo que os cerca. Isto é possível de ser investigado tanto pela análise de um único mito quanto de grupos de mitos e até mesmo da mitologia completa de uma sociedade (ROCHA, 1994, p. 12).

O mito, portanto, tem função social, alimenta e é alimentado por imaginários, comunicado 
pelas coletividades, e sua produção se assenta na região da mente humana que convencionalmente chama-se de inconsciente coletivo, espécie de depósito de sentidos que todos possuem das experiências coletivas.

O imaginário coletivo da população de Afuá é permeado de mitos, e neste artigo foram objeto de interesse os mitos do Kutruku e da Cobra Grande. Na documentação estudada aparecem menções a vários outros mitos, e importa destacar que essa mitologia revela os vínculos entre cultura e natureza, sincronia e diacronia, encerrando "[...] exatamente uma relação muito ligada às técnicas e formas de adaptação ao meio geográfico da região, seja ele florestal ou aquático" (RENTE NETO; FURTADO, 2015, p. 170).

\subsection{Kutruku}

O Kutruku talvez seja o mito de maior complexidade no panteão de seres encantados da cidade de Afuá. A grafia de seu nome varia entre Ku-truko, Cutrucu e Kutruku, sendo esse último o termo preferido neste texto. Sua aparência se caracteriza pela forma humana espectral, tal como assombração ou visagem. As fontes orais afirmam que o seu nome é uma alusão à sonoridade de seus movimentos pelas passarelas de madeira; mas também é atribuído ao som do barulho estridente das correntes que arrasta, ou ainda, da bengala na qual se apoia.

O Kutruku tem valor social, funciona no sentido de promover a coesão social em torno de regras de convivência, necessárias à sociabilidade em comunidades ribeirinhas, nas quais as relações entre humanos e natureza fazem parte das estratégias de sobrevivência. Observam-se duas versões do mito do Kutruku.

Primeira versão:

Há alguns anos a energia em nossa cidade funcionava das 18h às 21:00 horas.

As pessoas que conviviam na época contam que, nas noites de sexta-feira, a partir de zero hora aparecia um personagem estranho pelas ruas, que ficou conhecido pelo apelido de Kutruku. Uns diziam que era um padre sem cabeça, todo vestido de preto, outros diziam que era um homem muito bonito e alto, com um chapéu na cabeça, batendo com um bastão de madeira e arrastando uma corrente.

Esses dois instrumentos faziam um barulho estranho que aterrorizava as pessoas, deixando-as sem fala e sem poder de locomoção. Cada contador da lenda do Kutruku dá um toque especial à sua própria interpretação.

Dizem alguns contadores que o Kutruku rondava a cidade, fazendo aquele barulho esquisito e que, em frente à casa onde ele fizesse uma parada, a família residente tomava como um aviso, porque dentro de pouco tempo um de seus membros faleceria: Se alguém tentasse descobrir quem era o Kutruku, se olhasse pelas frestras das janelas, ficaria imobilizado. As domésticas a cada sexta feira recebiam a visita do Kutruku, para encontros amorosos. Se porventura os patrões acordassem, imediatamente ficavam adormecidos com uma sensação estranha e só retornavam a si quando o galo cantava, que era o horário em que o Kutruku se retirava (A LENDA do Kutruku, [195?]).

Segunda versão:

Com a finalidade de amedrontar as moças e as criançadas que insistiam em ficar fora de horas nas ruas os pais contavam que o ku-truku as pegariam, uma figura fantasiosa que possuía uma perna de pau e ao caminhar arrastava uma corrente nas pontes. Do som causado de sua perna de pau originou-se a pronúncia ku-truku (O MITO do Kutruku [195?]). 
Nas narrativas acima dispostas pode-se perceber o cenário que acompanha a narrativa do Kutruku: uma população que dormia ao apagar das luzes, pois o fornecimento de energia era racionado e após as 21:00 horas a iluminação era feita com lamparinas ${ }^{7}$. O Kutruku é o tipo de mito que serve para justificar relacionamentos entre humanos e encantados, e também serve como álibi para paixões proibidas, caso dos relacionamentos extraconjugais.

Outras questões merecem ser pontuadas: i) o Kutruku é uma figura noturna, aparecendo à meia-noite e sumindo com o cantar do galo, ao amanhecer; ii) o barulho do seu caminhar nas passarelas de madeira produz uma sonoridade que lhe nomeia; iii) às sextas-feiras as domésticas ${ }^{8}$ recebiam sua visita para encontros amorosos. O mais importante detalhe: o barulho emanado das passarelas de madeira sobre as águas, ou seja, "[...] natureza e cultura se encontram e um poderoso saber se espalha. Uma sociedade se expressa e uma forma existencial se perpetua. É o mito com seus enigmas e desafios" (ROCHA, 1994, p. 22).

No trabalho de observação em campo, alguns moradores especularam se o Kutruku teria ligação com o movimento de gado pelas passarelas de madeira da cidade de Afuá9. O interlocutor Gilbson Campos afirma que

[...] até hoje nós temos relatos de pessoas que chegaram a ver e que quando viam pela fresta da janela ficavam paralisadas. E só retornavam pela manhã, sabe? Então, eu tenho relato de dentro da família, eu tenho gente na minha família que até hoje conta e diz que quando ouviu o barulho foi lá pela fresta da janela e viu aquela pessoa alta e arrastando uma corrente e paralisou, e só retornou pela manhã (Informação Verbal). ${ }^{10}$

Dez interlocutores assumiram conhecer a figura do Kutruku, porém nenhum admitiu ter medo da visagem que outrora atormentava a vida dos moradores de Afuá. Tal constatação possibilita depreender que o mito perde gradativamente o valor social, ainda que não tenha desaparecido do imaginário afuaense. O esquecimento do Kutruku não é bem explicado por nenhum dos interlocutores, mas segue a lógica de transformação da própria cidade, visto que

As imagens podem ser recriadas na mente diante da memória, pois os seres humanos são despertados pelas imagens que vem à suas mentes. Estas mesmas imagens podem remeter a outras imagens em outros tempos, e esse despertar pode ligar a forma, a cor, ao cheiro, ao som. O imaginário trabalha interconexões diversas como, por exemplo, o medo, o pavor da morte, afetos, sonhos - daí a relação da ideia do sonhado, do não vivido. Intenciona decifrar significados de imagens visuais, verbais, mentais (VIGÁRIO, 2009, p. 6).

O Kutruku provoca naqueles que o veem desmaios, amnésia ou catatonia. Dito em outras palavras, as pessoas perdem sentidos, memória ou se tornam indiferentes em relação ao mundo exterior. Uma interlocutora assegurou que sua “[...] tia uma noite olhando pelas brechas da parede conseguiu ver o Kutruku, porém ficou paralisada; lembra até o momento de ter levantado e ter ido brechar. Depois disso ela não lembra mais nada" (Informação verbal). É correto afirmar, porém,

\footnotetext{
7 Pequena lâmpada que fornece luz de pouca intensidade, composta de um reservatório para líquido combustível (azeite, querosene etc.) no qual se mergulha um pavio que traspassa uma pequena rodela de madeira e se acende na outra extremidade.

8 Mulheres que trabalham em ambientes domésticos.

${ }^{9}$ Mesmo com a desconfiança do Kutruku estar relacionada com a passagem dos bois, as pessoas tinham medo de ir atestar a hipótese, e por isso o mistério se impunha sobre a criatura.

10 Programa comemorativo dos 129 anos de Afuá, transmitido pela rádio Afuá FM no dia 02 de agosto de 2019.
} 
que nem todos que mantinham contato com o encantado seriam alvo de sua malineza, mas ao contrário disso, cairiam em um estado de completa admiração ou sedução.

$\mathrm{Na}$ Figura 1 se contempla a imagem do contato homem-kutruku. A pintura faz representação de alguns aspectos que definem o modo de viver característico das populações marajoaras, tais como o paneiro carregando peixes, os chinelos de dedos, camisa e calça folgadas e tecidas com algodão rústico, elementos que fazem clara alusão ao antigo modo ribeirinho de viver.

$\mathrm{Na}$ face do homem há uma expressão de respeito pelo encantado e medo das consequências que a visão acarretará. O próprio ser encantado se apresenta de forma diferente da maioria das narrativas, não trajando nesta imagem o tradicional traje branco ou preto, tendo uma aparência física de visagem, com grandes garras, pé avantajado e dentes afiados, mas é em seu olhar e sorriso que estão projetadas as qualidades de assustador e malino ${ }^{11}$.

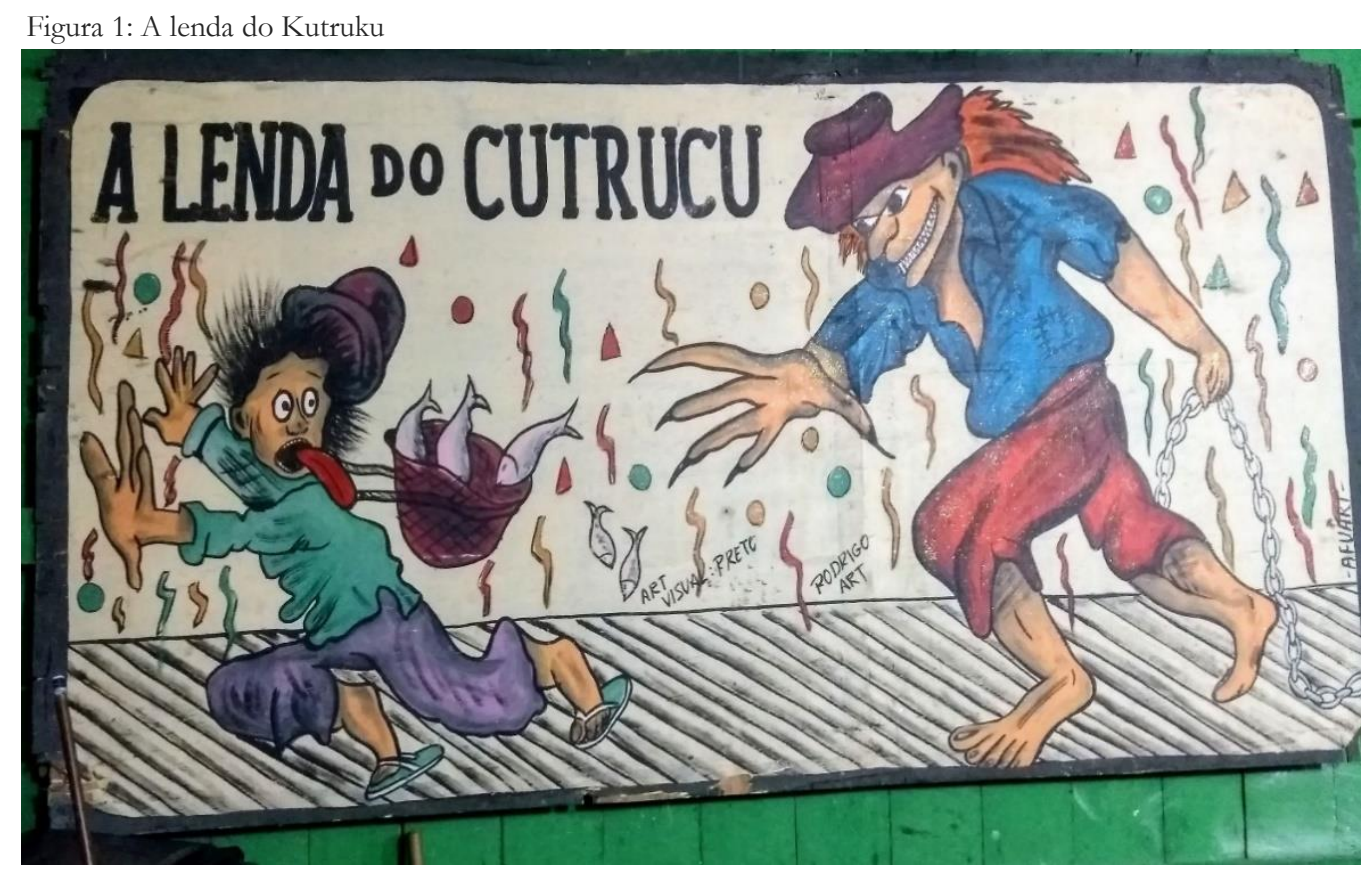

Fonte: AFUART ${ }^{12}$

O Kutruku, assim como o Boto, sai nas noites de luar em busca de vítimas para seu encantamento, e quando o efetiva deixa as moças seduzidas. Ao compor uma cantiga popular sobre o encantado Kutruku, Raimundo do Carmo assegura que

\footnotetext{
Na sexta-feira quando chegou meia-noite

Fui correndo pra janela pra ver o bicho passar

Abri a folha da janela de mansinho

E olhei devagarinho para não me assustar

Aí, ai meu Deus que grande susto que levei

O Kutruku era bonito logo me apaixonei

Me arrepiei com aquela perna e a corrente

Aproveita meu Kutruku que estou de sangue quente.

Kutruku, Kutruku, Kutruku, Kutruku
}

\footnotetext{
11 Mal em essência; em que há maldade.

12 A imagem está retratada numa pintura que está exposta no boteco Porta-joias, em Afuá, e sua autoria é atribuída aos artistas Preto e Rodrigo, que assinam a obra. Não tem datação, mas remonta à década de 2010.
} 
Lá, rá, lá, rá, rá, rá, rá

Ele é bonito, todo de branco

Só não sei quando ele vai voltar

Com o chapéu caído sobre o rosto

Volta Kutruku que eu vou te esperar (CHAGAS, [199?]).

O eu lírico da canção manifesta cautela na tentativa de encarar o "bicho", mas para sua surpresa o susto advém das características físicas do encantado, que "era bonito" e provoca paixão. No final da cantiga há um reforço nos aspectos de sua beleza e a vítima espera ansiosa pela volta do encantado. Existe nessas narrativas um reforço das relações homem-encantado que ora se apresentam de maneira trágica e ora se revelam como um romance, fruto das seduções próprias dos encantamentos.

O Kutruku é anunciado pelo ressoar de seus movimentos pelas passarelas de madeira, as quais estão sendo substituídas, devido à urbanização da cidade, por passarelas de concreto. Sem esse anúncio as aparições do encantado se tornam cada vez menos frequentes. A escuridão proveniente do apagar das luzes também foi alterada, considerando-se que atualmente o fornecimento de energia elétrica é regular durante as 24 horas. A modernização de Afuá, no que diz respeito à chegada de novas tecnologias e ao aprimoramento da infraestrutura urbana, faz com que o Kutruku se torne cada vez mais um mito em processo de esquecimento.

\title{
4.2 Cobra Grande
}

Nas águas da Amazônia, sejam rios, igarapés, lagos, ou qualquer outra formação aquática se precipitam significados que foram, no curso do tempo, se constituindo como personagens encantados. Nessa região se encontra em abundância a água doce, que "[...] é sempre privilegiada porque representa a primeira bebida, tão doce quanto o leite materno (PINTO, 2008, sem paginação)"; e é onde se localizam os reinos dos encantados, entidades como o Boto e a Cobra Grande ${ }^{13}$.

A Cobra Grande é aquele tipo de construção imagética encontrada em todos os imaginários amazônicos, e os habitantes de Afuá não são exceção. Segundo as narrativas, embaixo da Igreja de Nossa Senhora da Imaculada Conceição reside uma grande cobra que vive adormecida sob a influência da imagem da santa. Sua morada consiste em um grande túnel submerso que se inicia na margem do rio, seguindo até abaixo da igreja, onde ela se acomoda.

O mito adverte que se algum dia a imagem da Imaculada Conceição fosse retirada do altar despertaria a Cobra Grande e a cidade de Afuá seria completamente submergida. Tome-se para análise uma antiga cantiga popular que trata deste episódio, visto por muitos como o relato fiel do fim dos tempos, ou mesmo, do fim da história.

\section{Dança da Cobra Grande \\ Rema rema remador \\ Que a cobra vai te pegar \\ Ela vem cheia de fome}

\begin{abstract}
${ }^{13}$ A Cobra Grande é também conhecida em outros lugares da Amazônia com as denominações de Honorato ou Norato. Esses mitos narram que uma índia engravidou da Boiuna (serpente gigante que também faz parte do folclore brasileiro), tendo da gestação um casal de gêmeos. Ao observar que se tratavam de duas cobras procurou o líder de sua tribo para saber como deveria proceder: matava ou jogava no rio? 0 pajé informou que ela não poderia matá-las, pois morreria também, então a índia decidiu soltá-las no rio Tocantins. Disponível em: https://www.infoescola.com/folclore/cobra-grande/. Acesso em: 29 jul. 2020.
\end{abstract}


Pra comer o homem que não remar.

A maré encheu,

vazou o peixe ela comeu

Comeu o homem com a montaria

$\mathrm{E}$ até hoje não apareceu.

Ela mora debaixo da igreja

Sem que ninguém veja.

Se ela se mexer,

a coisa não vai prestar

Tudo vai por água abaixo

E a cidade afundar (DANÇA da cobra grande, [199?]).

A Cobra Grande encena um quadro de destruição e pavor nos imaginários amazônicos. No caso de Afuá, uma outra imagem se sobrepõe a esta: Nossa Senhora da Imaculada Conceição, a sacratíssima protetora da população. A própria Igreja Católica admitiu a existência do mito, na programação da festividade da santa no ano de 1996. À época escreveu Fr. Sebastián Olalla del Rio:

E o povo começou a pensar, a sonhar e a fazer uma grande Capela de madeira segundo uma planta de estilo gótico trazida da Itália pelo Pe. Salvador Tracaioli e que serviria de modelo E chegou uma Imagem grande, muito grande da Imaculada e muito linda, grande e muito pesada. E contam os ribeirinhos que quando foi colocada a cobra grande foi presa e não se move; só se se mover a estátua da santa é que se movimentará toda a igreja e toda a cidade. E é que Maria Imaculada é essa coluna forte, resistente e potente contra o maior inimigo, o demônio. Ela é sem pecado, pisou a sua cabeça (Gn, 3.15) (PARÓQUIA DE AFUÁ, 1996).

É interessante pensar que pela primeira vez a Igreja Católica se posicionou sobre o mito, não para lhe negar, mas para lhe justificar sob a lógica de que a imagem de Nossa Senhora da Conceição é a "coluna forte, resistente e potente" contra o inimigo. Nesta dimensão simbólica, ela é o esteio que mantém a Igreja de pé, e neste mesmo sentido também a cidade. Sem a proteção da santa a cidade padeceria sob as águas que lhe rodeiam.

A devoção à Nossa Senhora da Conceição protege a cidade da maldição da Cobra Grande, pois segundo o dogma católico Jesus Cristo foi concebido sem pecado original, que é simbolizado pela serpente. Conforme Dom Rodolfo Luís Weber, a imagem da Imaculada Conceição apresenta muitos itens, contudo nem sempre presentes em todas as representações, sendo a mais conhecida aquela em que "[...] Nossa Senhora está sobre o globo terrestre e esmaga a cabeça da serpente, símbolo do pecado original e a serpente fere o calcanhar, sinal de luta (WEBER, 2018, sem paginação)".

Com inspiração no argumento de Faulhaber (2000), afirma-se que a Cobra Grande representa a força do rio como elemento da natureza, por outro lado a festa da Imaculada Conceição garante a defesa contra essa permanente ameaça. O ápice da festa é o Círio, que acontece em três modalidades: terrestre, aéreo e fluvial (Figura 2). 
Figura 2: Círio fluvial de Nossa Senhora da Imaculada Conceição, Afuá-PA

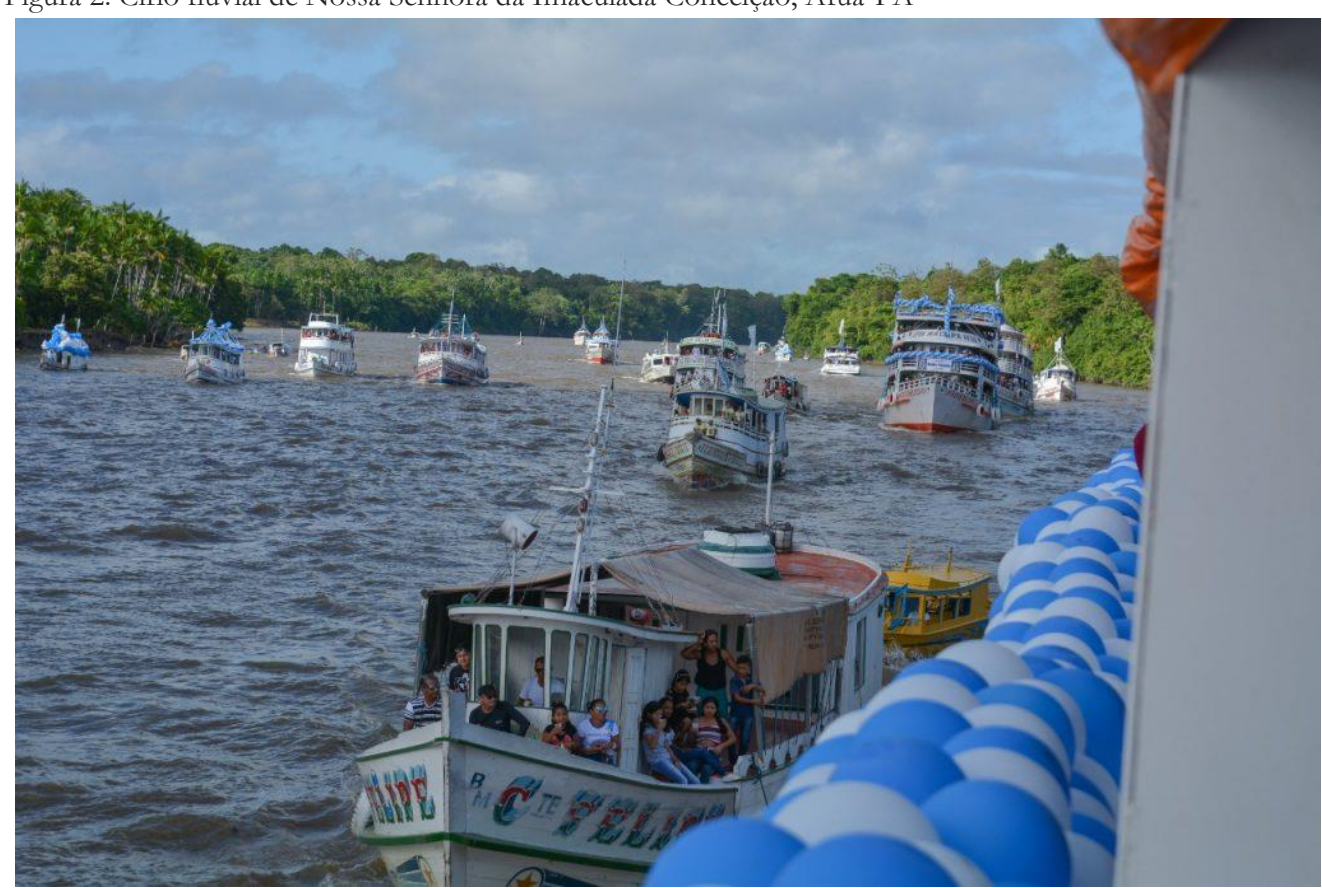

Fonte: Pantoja (2019)

$\mathrm{Na}$ relação entre a cobra grande e a Imaculada Conceição houve o episódio da demolição da Igreja Matriz por ocasião da ampliação de seu prédio. O projeto começou a ser idealizado no ano de 2001 e a obra foi concluída em 2007. No entanto, durante esse processo a população da cidade se mostrou temerosa em relação à derrubada do prédio antigo, pois isso significava a retirada da imagem da Santa do seu altar, deixando a cidade sem proteção diante da ameaça da completa submersão. Observe-se a conversa entre os moradores Gilbson Campos e Emercindo Vilhena:

Gilbson Campos: Tanto é que quando frei Cléto, [na ocasião] pároco de Afuá decidiu derrubar a igreja para construir esta atual, então no dia marcado para a retirada da imagem...

Emercindo Vilhena: O povo ficou com medo não foi?

Gilbson Campos: Muita gente viajou para Macapá e houve rumores de que quando foi tirada a imagem já estavam rachando as terras lá no final do Capim Marinho, e o povo ia correndo para avisar, enfim. Então são lendas, são histórias que ficam, apesar de nós já termos uma igreja nova, essa parte do alicerce, essa parte [interrupção externa] ela continua. E tem muita gente que, já vieram mergulhadores de fora aqui para o município em algumas ocasiões e já mergulharam aí em frente à igreja e disseram que existe um buraco muito grande que vai para debaixo da igreja e aqui suga, aquilo lá suga. Então eles relatam isso, e relatam [interrupção externa]... então Afuá é cheia de lendas, cantos e encantos [interrupção externa], mistérios a serem decifrados ainda, enfim (Informação Verbal). ${ }^{14}$

Este evento tem especial importância, pois a partir dele o imaginário coletivo reverbera de modo particular expressando as inquietações dos moradores naquilo que parece ser um "tempo quente na produção de imaginários”, conforme registrou Baczko (1991, p. 39 apud ESPIG, 2004), momento em que "durante um conflito social (ou 'comoção de estruturas') a imaginação poderá sofrer um ímpeto particular, ocorrendo uma produção acelerada de significações para os acontecimentos".

${ }^{14}$ Conversa registrada no Programa Comemorativo dos 129 anos de Afuá, programa informativo da Prefeitura Municipal de Afuá, transmitido pela rádio Afuá FM no dia 02 de agosto de 2019. 
O desfecho adveio com a reunião de um grupo de fiéis em frente à igreja à espera de que o pior pudesse acontecer. "Parecia haver um desespero coletivo naquele dia, mas para a surpresa de todos nada aconteceu" (Informação verbal). Ou melhor, aconteceu aquilo que Rocha (1994, p. 48) considerou a produção de um novo mito. Segundo ele, "[...] o mito se deixa eternamente interpretar, e esta interpretação torna-se, ela mesma, um novo mito. Em outras palavras, as interpretações não esgotam o mito. Antes, de outra maneira, a ele se agregam como novas formas de o mito expor suas mensagens". Desta forma, o mito da Cobra Grande, na tentativa de ser enquadrado em uma forma interpretativa, assume várias outras narrativas.

Agora a noção de existência da Cobra Grande assume duas interpretações: na primeira o mito, ao contrário de ser esquecido, se ressignificou, o encantado é real e ainda permanece adormecido nas águas embaixo da igreja, mas agora a cobra somente despertará se a imagem da Santa sair da cidade; na segunda assume-se que a Cobra Grande existe, mas agora não está mais onde deveria estar; por alguma razão desconhecida o encantado teria ido embora.

\section{Considerações finais}

Pode-se vislumbrar as significações e ressignificações na composição de narrativas que revelam no presente as vivências do passado e as projeções do futuro, numa dialética entre o conceber, ser e agir no mundo. Espera-se contribuir com as reflexões sobre a complexa constelação social encontrada na Amazônia, cuja história “[...] é marcada por silêncios e ausências que acentuam a sua relativa invisibilidade e velam os traços configurativos da sua identidade" (FRAXE; WITKOSKI; MIGUEZ, 2009, p. 30).

Afuá, como outras cidades amazônicas, tem suas configurações materiais e simbólicas resultantes dos variados modos de pensar e existir no espaço-tempo de suas populações. Da mitologia afuaense é possível extrair os significados que da história vivida foram constituindo as subjetividades que orientam pensamentos e comportamentos, cujo escrutínio é imperioso à elaboração de políticas públicas para a Amazônia.

\section{Referências}

A LENDA do Kutruku. Documento. Afuá: Biblioteca Pública Municipal de Afuá Professora Belkiss Santos [195?]. (Coleção de documentos aleatórios da cidade de Afuá/PA)

BARCA, Isabel. Investigar em educação histórica em Portugal: opções metodológicas. Educar em Revista, Curitiba, Brasil, v. 35, n. 74, p. 109-126, mar./abr. 2019.

BARROS, José D’Assunção. História, Imaginário, mentalidades: delineamentos possíveis. Conexão - Comunicação e Cultura, Caxias do Sul: UCS, v. 6, n. 11, jan./jun. 2007.

CHAGAS, Raimundo do Carmo. Dança do Kutruku. Canção. [199?].

DANÇA da cobra grande. Cantiga popular. [199?].

DIAS, Mario Benjamim; SILVA, Maria de Jesus Benjamim. Afuá: Veneza Marajoara, Pará-Brasil. Revista Geográfica de América Central Número Especial EGAL, Costa Rica, p. 1-18, 2011.

ESPIG, Márcia Janete. O conceito de imaginário: reflexões acerca de sua utilização pela História. Textura, Canoas, n. 9, p. 49-56, nov. 2003-jun. 2004.

FAULHABER, Priscila. Refletindo sobre as máscaras Ticuna. Reunião Anual da ANPOCS, 24, 2000, Petrópolis. Anais. Petrópolis, 23 a 27 out. 2000. Disponivel em: http://www.anpocs.com/ 
index.php/encontros/papers/24-encontro-anual-da-anpocs/gt-22/gt04-12/4746-pfaulhaber-refletindo/file. Acesso em: 28 jul. 2020.

FRAXE, Therezinha de Jesus Pinto; WITKOSKI, Antônio Carlos; MIGUEZ, Samia Feitosa. O ser da Amazônia: identidade e invisibilidade. Ciência e cultura, São Paulo, v. 61, n. 3, p. 30-32, 2009.

HARTOG, François. Regimes de historicidade: presentismo e experiências no tempo. 1 ed.; 1 reimp. Belo Horizonte: Autêntica, 2014. (Coleção história e historiografia)

IBGE - Instituto Brasileiro de Geografia e Estatística. Biblioteca digital do IBGE. Rua Cipriano Santos em Afuá (PA). Disponivel em: https://biblioteca.ibge.gov.br/index.php/biblioteca-catalogo?view= detalhes\&id=42315. Acesso em 04 de janeiro de 2019.

IBGE - Instituto Brasileiro de Geografia e Estatística. Estimativa da população residente com data referência 1 de julho de 2014. Rio de Janeiro: IBGE, 2014. Disponível em: https://cidades.ibge.gov.br/brasil/pa/afua/panorama/. Acesso em: 07 jan. 2019.

LAPLANTINE, François; TRINDADE, Liana. O que é imaginário. São Paulo: Brasiliense, 2003. (Coleção primeiros passos)

O MITO do Kutruku. Documento. Afuá: Biblioteca Pública Municipal de Afuá Professora Belkiss Santos [195?]. (Coleção de documentos aleatórios da cidade de Afuá/PA)

PACHECO, Agenor Sarraf. Religiosidade afroindígena e natureza na Amazônia. Horizonte, Belo Horizonte, v. 11, n. 30, p. 476-508, abr./jun., 2013. Disponivel em: https://dialnet.unirioja.es/servlet/articulo?codigo=4400385. Acesso em: 12 set. 2019.

PANTOJA, Railana. Círio de Nossa Senhora da Conceição reunirá milhares de fiéis em Afuá (PA). Diario. 14 nov. 2019. Não paginado. Disponível em: https://www.diariodoamapa.com.br/cadernos/cidades/cirio-de-nossa-senhora-da-conceicao-reunira-milhares-de-fieis-em-afua-pa/. Acesso em: 31 jul. 2020.

PARÓQUIA DE AFUÁ. Festividade de Nossa Senhora da Conceição. Afuá, 1983. Biblioteca Pública Municipal de Afuá Professora Belkiss Santos.

PARÓQUIA DE AFUÁ. Festividade de Nossa Senhora da Conceição. Afuá, 1994. Biblioteca Pública Municipal de Afuá Professora Belkiss Santos.

PARÓQUIA DE AFUÁ. Festividade de Nossa Senhora da Conceição. Afuá, 1996. Biblioteca Pública Municipal de Afuá Professora Belkiss Santos.

PARÓQUIA DE AFUÁ. Festividade de Nossa Senhora da Conceição. Afuá, 2001. Biblioteca Pública Municipal de Afuá Professora Belkiss Santos.

PARÓQUIA DE AFUÁ. Festividade de Nossa Senhora da Conceição. Afuá, 2003. Biblioteca Pública Municipal de Afuá Professora Belkiss Santos.

PARÓQUIA DE AFUÁ. Festividade de Nossa Senhora da Conceição. Afuá, 2012. Biblioteca Pública Municipal de Afuá Professora Belkiss Santos.

PESAVENTO, Sandra Jatahy. História \& História Cultural. 3. ed.; 1 reimp. Belo Horizonte: Autêntica, 2014.

PINTO, Marilina C. Oliveira Bessa Serra. Amazônia e o imaginário das águas. Encontro da Região Norte da Sociedade Brasileira de Sociologia, 1, 16 out. 2008, Manaus. Anais. Manaus: Programa de Pós-Graduação em Sociologia PPGS/UFAM, 2008. Trabalho apresentado na mesa-redonda Populações Amazônicas. Disponível em: http://ppgsocio.ufam.edu.br/attachments/038_A\%20A maz\%C3\%B4nia\% 2 0e\%20o\%20imagin\%C3\%A1rio\%20das\%20\%C3\%A1guas.pdf. Acesso em 28 de jul. 2020.

RENTE NETO, Francisco; FURTADO, Lourdes Gonçalves. A ribeirinidade amazônica: algumas reflexões. Cadernos de Campo, São Paulo, v. 24, n. 24, p. 158-182, 2015. 
ROCHA, Everardo. O que é mito. 6. ed. São Paulo: Brasiliense, 1994. (Coleção primeiros passos, 151)

SIMÕES, Vanessa Cristina Ferreira. Ideadores de bicitáxi: Cartografia de experiências estéticas em modos de viver e fazer bicitáxis na Veneza Marajoara (Afuá - PA). 2014. Dissertação (Mestrado) Universidade Federal do Pará, Belém, 2014.

VAINFAS, Ronaldo. História das mentalidades e história cultural. In: CARDOSO, Ciro F.; VAINFAS, Ronaldo (org.). Domínos da história: ensaios de teoria e metodologia. Rio de Janeiro: Campus, 1997.

VIGARIO, Jaqueline Sirqueira. História e Imaginário. In: II Seminário de Pesquisa da Pós-Graduação em História UFG/UCG. 2009, Goiânia. Disponivel em: https://pos.historia.ufg.br/up/113/o/ IISPHist09_JaquelineSgario.pdf. Acesso em: 29 jun. 2018.

WEBER, Rodolfo Luís. Nossa Senhora da Conceição. CNBB. Igreja Católica Apostólica Romana. 08 dez. 2018. Disponível em: https://www.cnbb.org.br/nossa-senhora-da-conceicao/. Acesso em: 30 jul. 2020.

Artigo recebido em: 13/05/2020

Artigo aceito em: 18/08/2020 